\title{
Butterfly-Inspired 2D Periodic Tapered-Staggered Subwavelength Gratings Designed Based on Finite Difference Time Domain Method
}

\author{
Houxiao Wang, ${ }^{1,2,3}$ Wei Zhou, ${ }^{2,3}$ Er Ping Li, ${ }^{3}$ and Rakesh Ganpat Mote ${ }^{3,4}$ \\ ${ }^{1}$ School of Mechanical Engineering, Jiangsu University, 301 Xuefu Road, Zhenjiang 212013, Jiangsu, China \\ ${ }^{2}$ School of Mechanical and Aerospace Engineering, Nanyang Technological University, 50 Nanyang Avenue, Singapore 639798 \\ ${ }^{3}$ Advanced Photonics and Plasmonics Division, A STAR Institute of High Performance Computing, 1 Fusionopolis Way, \\ No. 16-16 Connexis, Singapore 138632 \\ ${ }^{4}$ Department of Mechanical Engineering, Indian Institute of Technology Bombay, Powai, Mumbai 400076, India
}

Correspondence should be addressed to Houxiao Wang; wanghx@ujs.edu.cn, Wei Zhou; wzhou@cantab.net, and Er Ping Li; eplee@ihpc.a-star.edu.sg

Received 19 October 2014; Revised 23 December 2014; Accepted 18 January 2015

Academic Editor: Yaling Liu

Copyright (C) 2015 Houxiao Wang et al. This is an open access article distributed under the Creative Commons Attribution License, which permits unrestricted use, distribution, and reproduction in any medium, provided the original work is properly cited.

The butterfly-inspired 2D periodic tapered-staggered subwavelength gratings were developed mainly using finite difference time domain (FDTD) method, assisted by using focused ion beam (FIB) nanoscale machining or fabrication. The periodic subwavelength structures along the ridges of the designed gratings may change the electric field intensity distribution and weaken the surface reflection. The performance of the designed $\mathrm{SiO}_{2}$ gratings is similar to that of the corresponding $\mathrm{Si}$ gratings (the predicted reflectance can be less than around $5 \%$ for the bandwidth ranging from $0.15 \mu \mathrm{m}$ to $1 \mu \mathrm{m}$ ). Further, the antireflection performance of the designed $x$-unspaced gratings is better than that of the corresponding $x$-spaced gratings. Based on the FDTD designs and simulated results, the butterfly-inspired grating structure was fabricated on the silicon wafer using FIB milling, reporting the possibility to fabricate these FDTD-designed subwavelength grating structures.

\section{Introduction}

Nowadays, there is an increasing trend to learn from nature to analyze natural structures and develop bioinspired devices/elements through mimicking or replicating natural structures [1-11]. It has been reported that the moth eyes have inspired the researchers to develop antireflective structured photovoltaic materials and devices (e.g., solar cells) for higher light-to-electricity conversion efficiency [12-18], and the lotus leaves have excited the investigators to design the selfcleaning/hydrophobic structures or surfaces $[19,20]$. Like the nanostructures of moth eyes and lotus leaves, the structures of butterfly wings, which may contribute to their own colors $[2,5-10,21-30]$, carry the potential to develop new materials, techniques, and devices for different applications.

The reported butterfly-inspired technologies/products consist of the hydrophobic or self-cleaning materials/surfaces
$[6-8,21,22]$, the high-efficiency solar panels $[5,9,23,24]$, the vapor or gas nanosensors $[6,8,10,25]$, the iridescent $\mathrm{ZrO}_{2}$ photonic crystals [26], the optical beam splitter [27], and the magnetooptic structures [28]. Differently, in this study, the butterfly-inspired newly designed 2D periodic taperedstaggered subwavelength gratings were developed using finite difference time domain (FDTD) simulation method, assisted by using focused ion beam (FIB) nanoscale machining or fabrication (the already achieved grating designs and their antireflection performance were obtained based on FDTD simulation).

\section{Materials and Methods}

The butterfly species used in this study consisted of the Palm King and the Hebomoia leucippe. The FIB system was used 


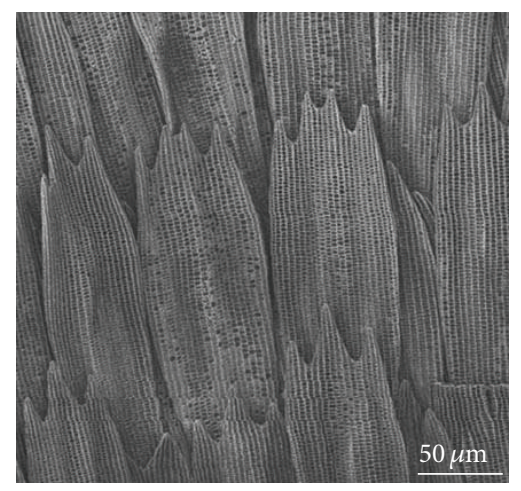

(a)

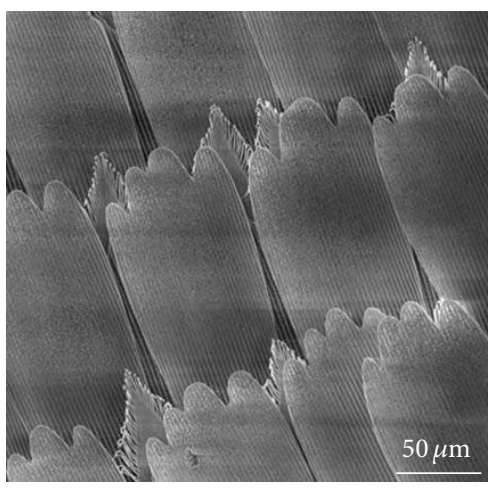

(b)

Figure 1: Pigmented microscales on butterfly wings for (a) Palm King and (b) Hebomoia leucippe.

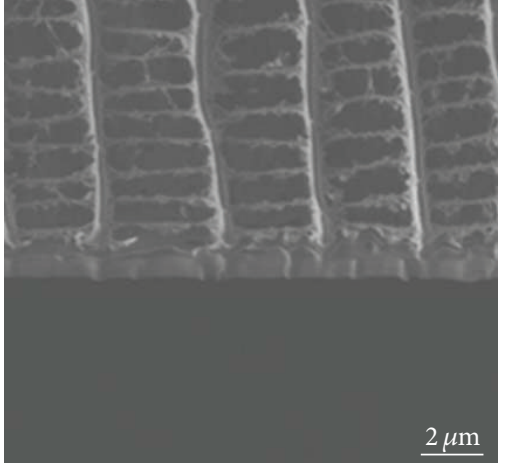

(a)

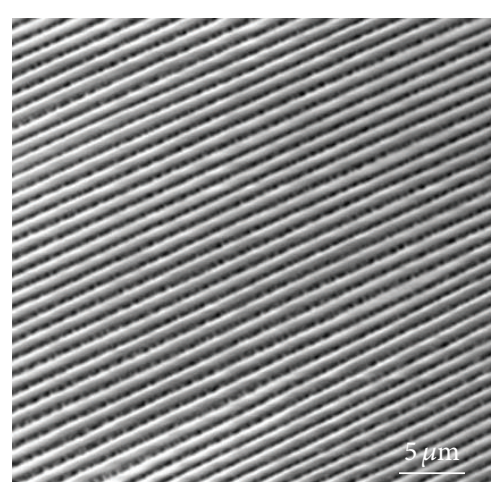

(b)

FIgURE 2: (a) Cross section after removing pigment granules using FIB and (b) flute-like gratings in the wing scales of Hebomoia leucippe.

for nanomachining and imaging. The FDTD method was utilized for design and optical performance computation. The designed grating structure was fabricated on the silicon wafer.

\section{Structural Analysis for Butterfly Wings Using FIB Nanomachining}

The butterfly wings are the translucent and/or pigmented chitin membranes covered with lots of transparent and/or pigmented microscopic light-interacting scales. These microscales may have the function for coloration, waterproofing characteristics (repel water-like roof tiles), and/or solar energy collection (Figure 1). These thin and nanopatterned chitin scales overlap one another, which may allow the dynamic control of light flow and photon interaction by selectively filtering out certain wavelengths through refraction, interference, and/or absorption while reflecting others for visual colorations, subject to the real scale structure and the scale layer distance.

The structures in the scales of the observed butterfly wings are shown in Figures 2 and 3. The general structures in each wing scale are grating-based which consist of the taper- or flute-shaped longitudinal ridges with subwavelength grating substructures and the transverse ribs with/without ovoid pigment granules. The pigment granules on the cross ribs of the wing scales of the Hebomoia leucippe can be removed using FIB, and the exposed structures after FIB nanomachining are shown in Figures 2(a) and 3(b), which appear similar to those of the Palm King (Figure 3(a)) despite the flute-like grating structures shown in Figure 2(b).

\section{2D Periodic Tapered-Staggered Subwavelength Gratings}

The inverse- $\mathrm{V}$ structures of the black wings of butterfly Ornithoptera goliath may achieve good antireflection property $(99 \%$ absorption and $1 \%$ reflection in visible light spectrum $380-795 \mathrm{~nm}$, the reflectance of the reverse Vtype surface is around $1 / 13$ of that in the flat plate). Thus, they show promising antireflection applications for the optical instruments, sensors, thermal detectors, and solar cells [24]. However, as shown in Figure 3, the observed tapered grating ridges have lots of subwavelength periodic grating substructures, whose antireflection performance has not been reported, without mentioning the other functions of these ridge-directional subwavelength periodic grating substructures. 


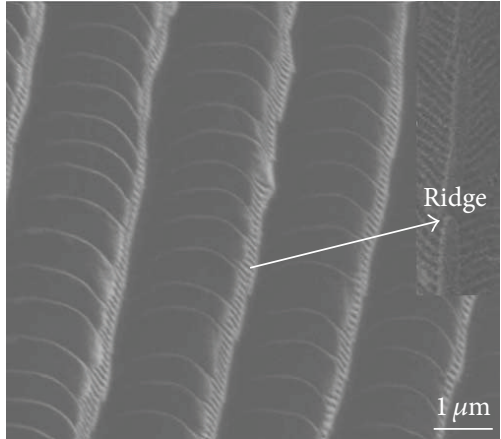

(a)

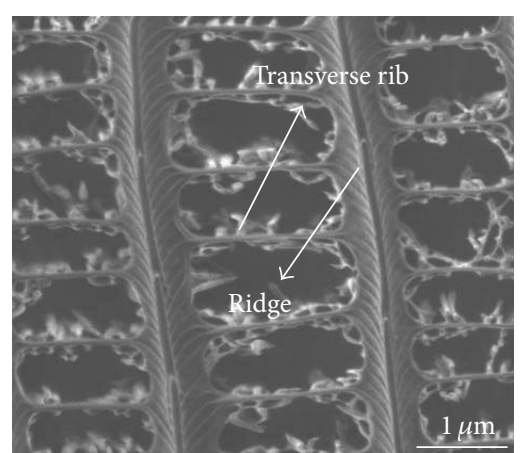

(b)

Figure 3: Subwavelength structures in the wing scales for (a) Palm King and (b) Hebomoia leucippe.

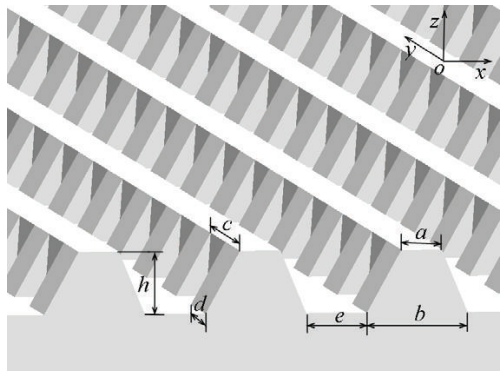

(a)

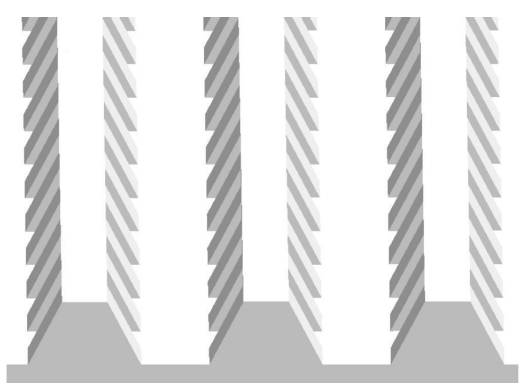

(b)

FIGURE 4: FDTD design of $x$-spaced 2D periodic tapered-staggered gratings.

TABLE 1: Geometry parameters for $\mathrm{SiO}_{2}$ gratings designed in Figure 4 .

\begin{tabular}{lccccc}
\hline$a(\mathrm{~nm})$ & $b(\mathrm{~nm})$ & $c(\mathrm{~nm})$ & $d(\mathrm{~nm})$ & $e(\mathrm{~nm})$ & $h(\mathrm{~nm})$ \\
\hline 100 & 200 & 200 & 100 & 100 & 100 \\
\hline
\end{tabular}

TABLE 2: Geometric dimensions for gratings designed in Figure 5.

\begin{tabular}{lcccc}
\hline$a(\mathrm{~nm})$ & $b(\mathrm{~nm})$ & $c(\mathrm{~nm})$ & $d(\mathrm{~nm})$ & $h(\mathrm{~nm})$ \\
\hline 50 & 100 & 100 & 50 & 200 \\
\hline
\end{tabular}

Accordingly, inspired by the nanostructures observed in the scales of the butterfly wings (Figure 3), the 2D periodic tapered-staggered subwavelength gratings were developed. The designed 2D periodic tapered-staggered subwavelength gratings are shown in Figures 4 and 5 (the mimic design of the grating structures of the observed butterfly wings), and the designed grating dimensions are given in Tables 1 and 2. The calculated normal-incident reflectance for the designed gratings at various wavelengths and polarization angles is given in Figures 6-8, where the reference axis for the polarization angles $\left(0^{\circ}\right.$ and $\left.90^{\circ}\right)$ is the $x$-axis.

Different from the reflective performance of the general right-angled gratings (geometric dimensions designed: $\Lambda=$
$200 \mathrm{~nm}, F=50 \%$, and $h=200 \mathrm{~nm}$ ), the periodic subwavelength structures along the ridges of the 2D periodic taperedstaggered gratings may change the electric field intensity distribution (sensitive to light polarization) and weaken the surface reflection (Figure 6). Moreover, the performance of the designed 2D periodic tapered-staggered subwavelength $\mathrm{SiO}_{2}$ gratings is similar to that of the corresponding $\mathrm{Si}$ gratings, and the predicted reflectance can be less than around 5\% for the bandwidth ranging from $0.15 \mu \mathrm{m}$ to $1 \mu \mathrm{m}$ (Figure 7). In addition, as shown in Figures 7 and 8, the antireflection performance of the gratings designed in Figure 5 and Table 2 is better than that of the gratings designed in Figure 4 and Table 1.

On the basis of the FDTD designs and simulated results, as shown in Figure 9, the butterfly-inspired 2D periodic tapered-staggered subwavelength grating structure was fabricated on the silicon substrate using FIB milling for reporting the possibility to fabricate these FDTD-designed grating structures.

\section{Conclusions}

The butterfly-inspired 2D periodic tapered-staggered subwavelength gratings were newly developed mainly using the FDTD method. The normal-incident reflectance of the 


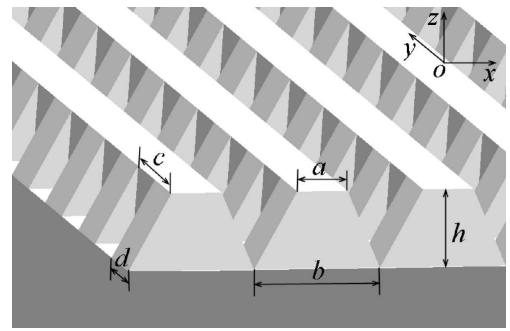

(a)

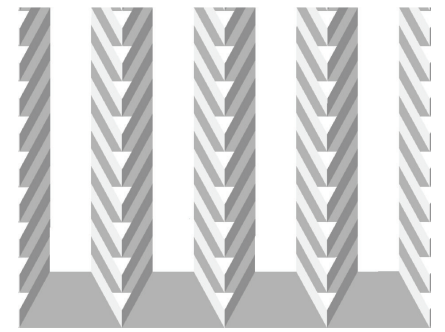

(b)

FIGURE 5: FDTD design of $x$-unspaced 2D periodic tapered-staggered gratings.
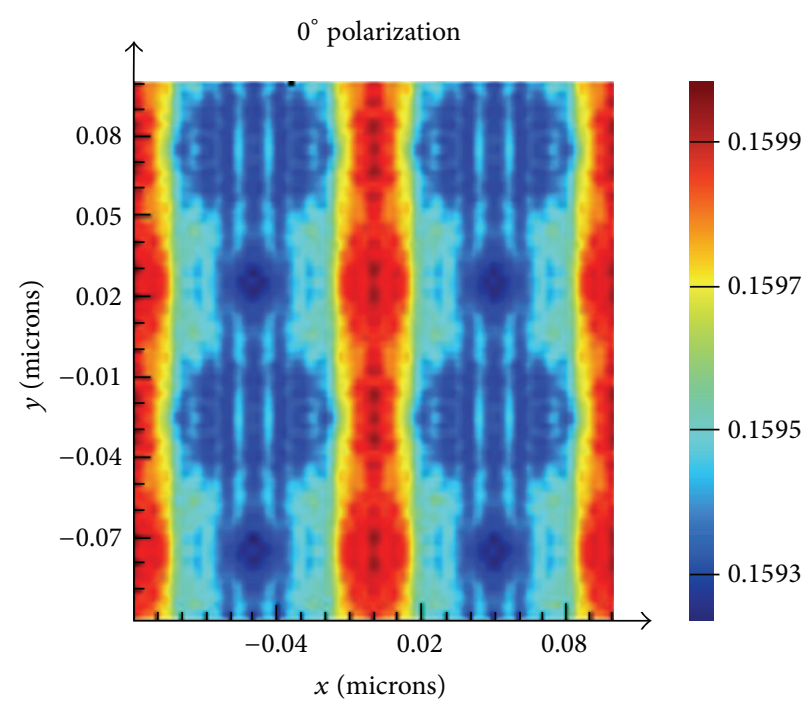

(a)

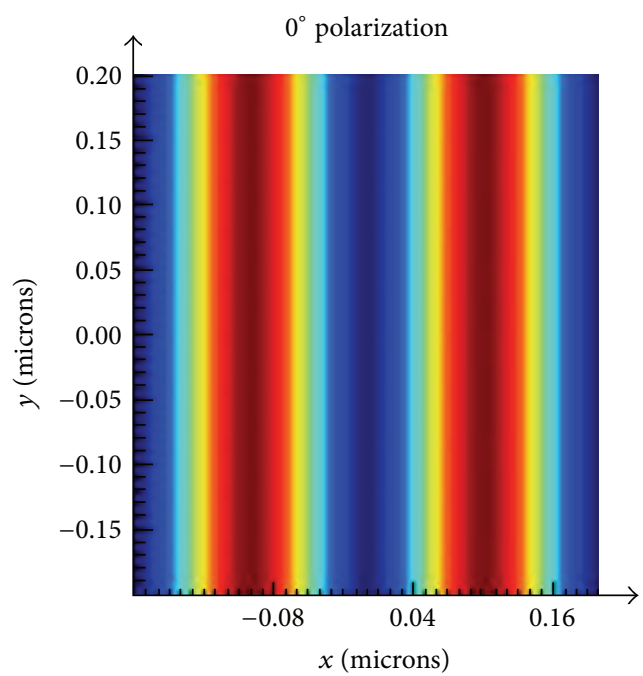

(a)
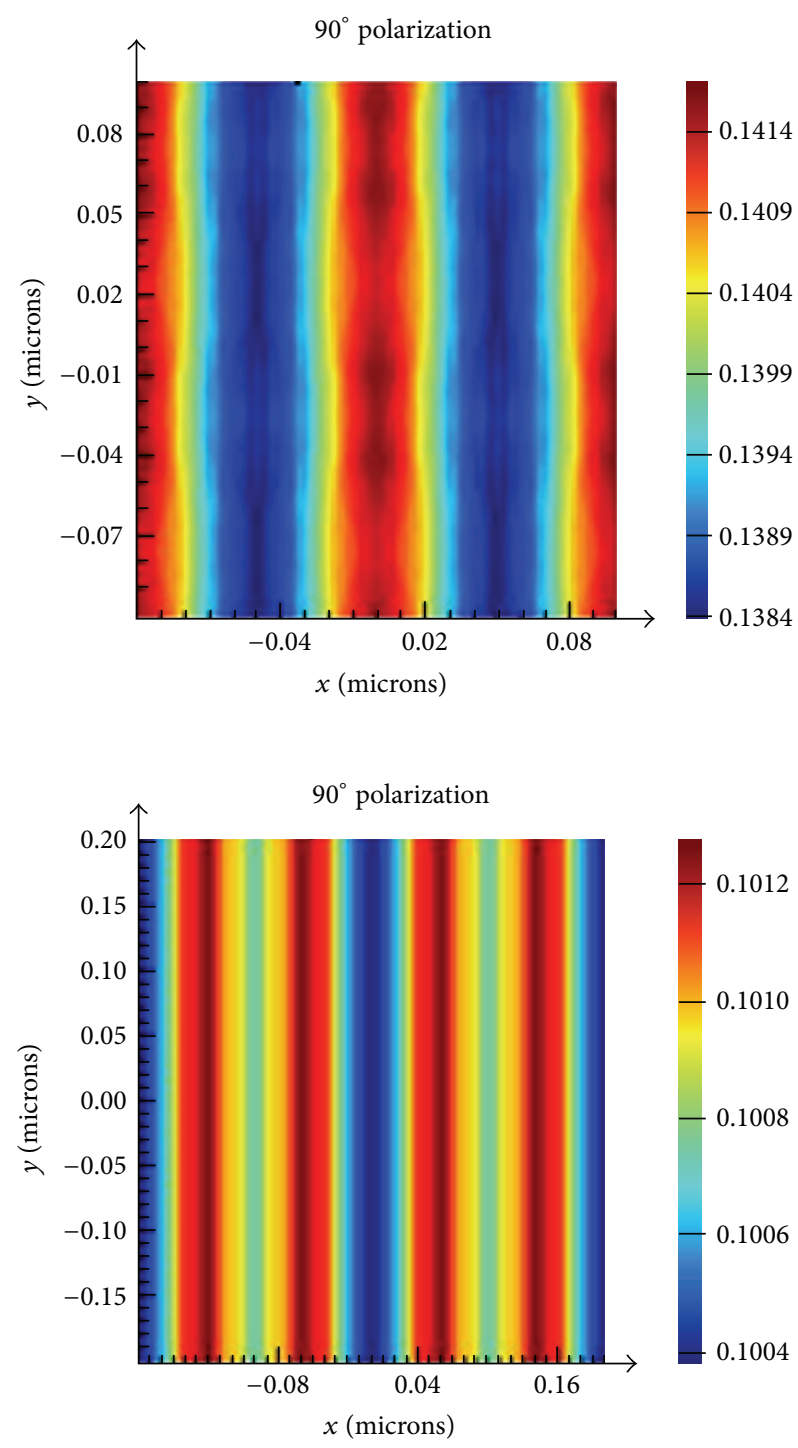

(b)

FIGURE 6: Calculated reflected electric intensity distributions for (a) $x$-unspaced 2D periodic tapered-staggered and (b) general right-angled Si gratings. 

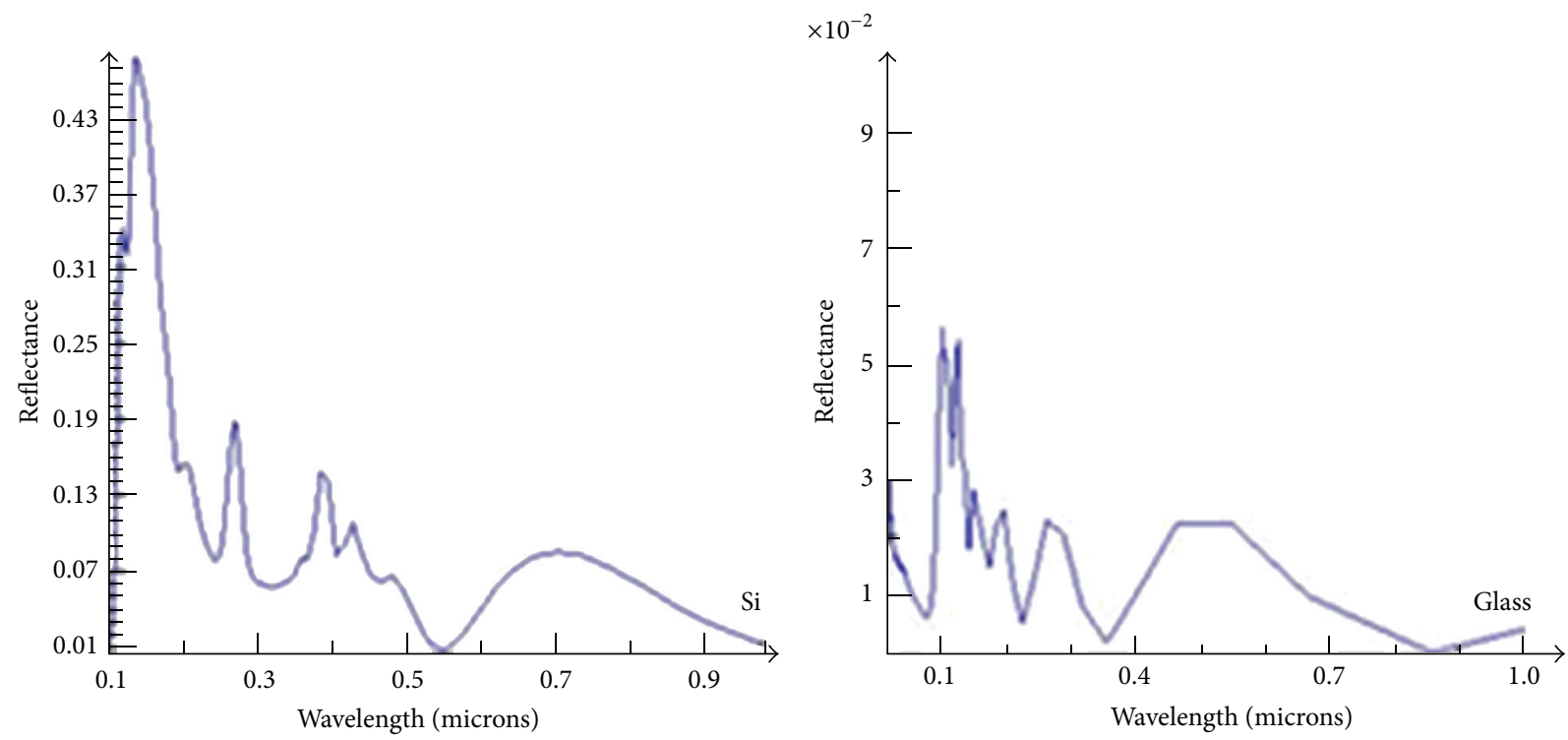

(a)
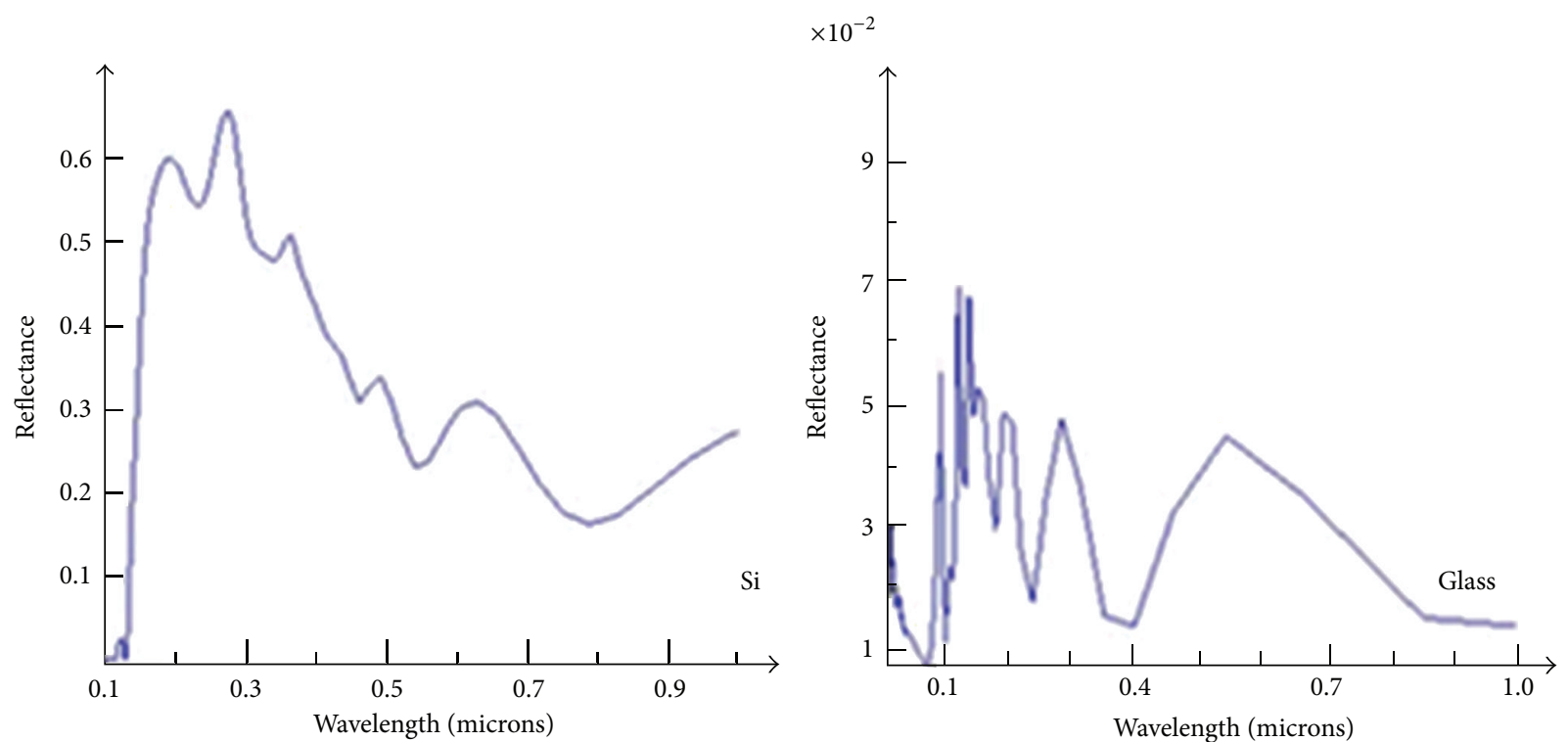

(b)

FIGURE 7: Calculated reflectance at various wavelengths for $x$-unspaced 2D periodic tapered-staggered gratings at (a) $0^{\circ}$ and (b) $90^{\circ}$ polarization.

designed gratings at different wavelengths and polarization angles was analyzed. It was shown that the $2 \mathrm{D}$ periodic tapered-staggered subwavelength gratings have different reflective performance from those of the general right-angled gratings. Moreover, the periodic subwavelength substructures along the ridges of the designed gratings may change the electric field intensity distribution (sensitive to light polarization) and weaken the surface reflection. Further, the performance of the designed $\mathrm{SiO}_{2}$ gratings is similar to that of the corresponding $\mathrm{Si}$ gratings, and the predicted reflectance can be less than around 5\% for the bandwidth ranging from $0.15 \mu \mathrm{m}$ to $1 \mu \mathrm{m}$. The antireflection performance of the designed $x$-unspaced gratings is better than that of the corresponding $x$-spaced gratings. Based on the FDTD designs and simulated results, the butterfly-inspired 2D periodic tapered-staggered subwavelength grating structure was fabricated on the silicon substrate using FIB milling, reporting the possibility to fabricate these FDTD-designed grating structures.

\section{Conflict of Interests}

The authors declare that there is no conflict of interests regarding the publication of this paper. 


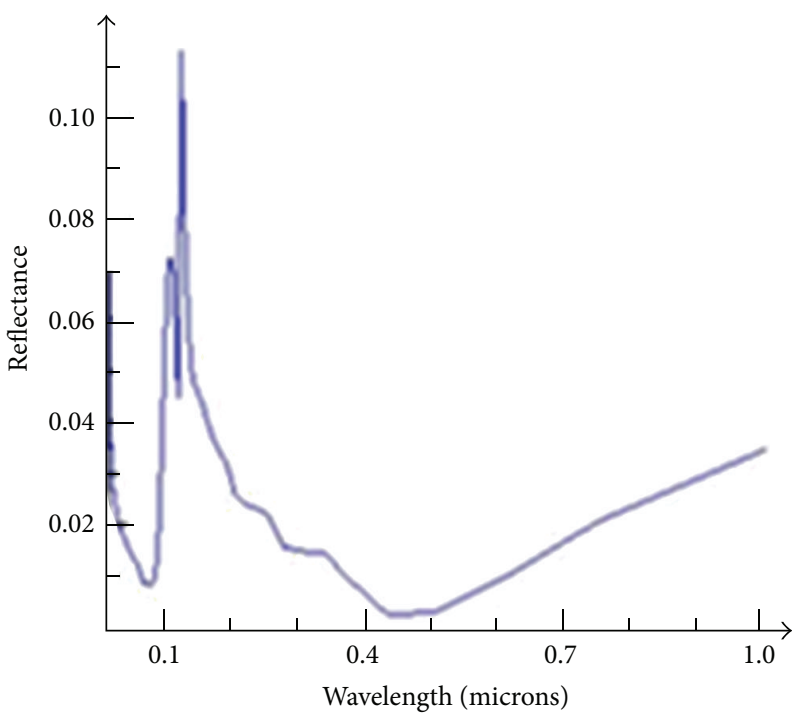

(a)

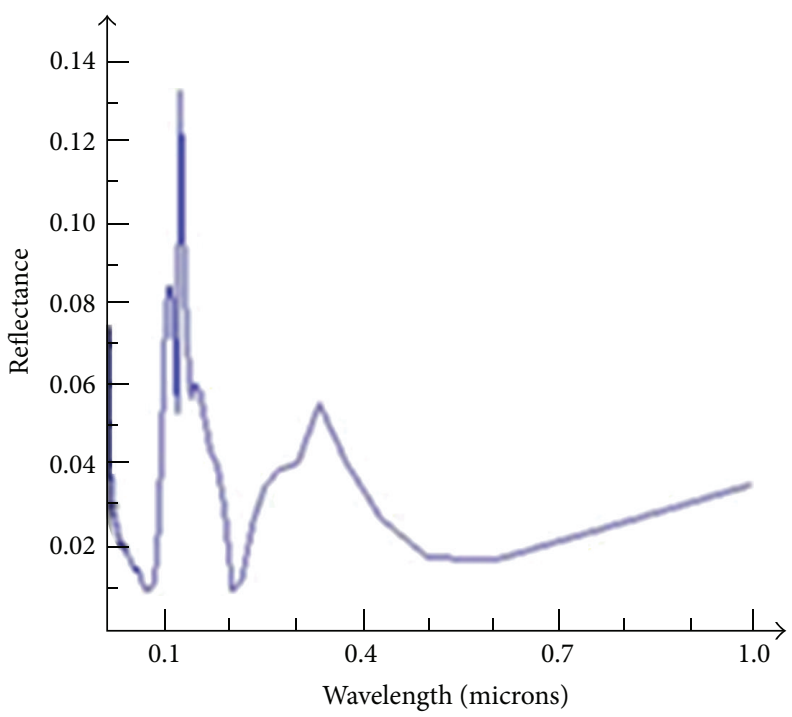

(b)

FIgURE 8: Calculated reflectance at various wavelengths for $x$-spaced $2 \mathrm{D}$ periodic tapered-staggered $\mathrm{SiO}_{2}$ gratings at (a) $0^{\circ}$ and $(\mathrm{b}) 90^{\circ}$ polarization.

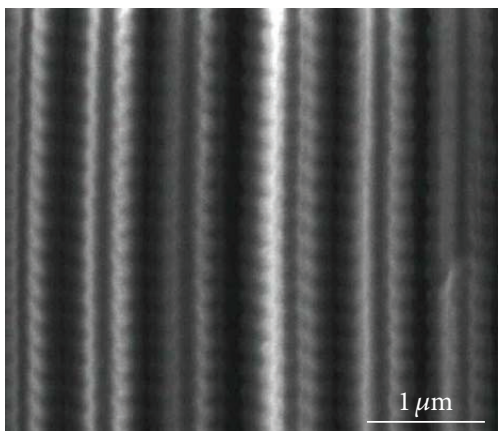

FIGURE 9: FIB-fabricated 2D periodic tapered-staggered subwavelength $\mathrm{Si}$ gratings measured using scanning electron microscope.

\section{Acknowledgments}

The work is supported by the Research Foundation for Advanced Talents of Jiangsu University under Grant no. 14JDG020, China, and the A STAR (Agency for Science, Technology and Research) under SERC Grant no. 072101 0023, Singapore.

\section{References}

[1] Y. Li, J. Zhang, and B. Yang, "Antireflective surfaces based on biomimetic nanopillared arrays," Nano Today, vol. 5, no. 2, pp. 117-127, 2010.

[2] H. X. Wang, W. Zhou, and E. P. Li, "Focused ion beam nanoprecision machining for analyzing photonic structures in butterfly," Key Engineering Materials, vol. 447-448, pp. 174-177, 2010.

[3] Y. Hou, B. L. Abrams, P. C. K. Vesborg et al., "Bioinspired molecular co-catalysts bonded to a silicon photocathode for solar hydrogen evolution," Nature Materials, vol. 10, no. 6, pp. 434-438, 2011.

[4] J.-W. Yoo, D. J. Irvine, D. E. Discher, and S. Mitragotri, "Bioinspired, bioengineered and biomimetic drug delivery carriers," Nature Reviews Drug Discovery, vol. 10, no. 7, pp. 521-535, 2011.

[5] D. Zhang, W. Zhang, J. Gu et al., "Bio-Inspired functional materials templated from nature materials," KONA Powder and Particle Journal, vol. 28, pp. 116-130, 2010.

[6] K. Liu and L. Jiang, "Bio-inspired design of multiscale structures for function integration," Nano Today, vol. 6, no. 2, pp. 155-175, 2011.

[7] Z. Guo, W. Liu, and B.-L. Su, "Superhydrophobic surfaces: from natural to biomimetic to functional," Journal of Colloid and Interface Science, vol. 353, no. 2, pp. 335-355, 2011.

[8] F. Song, H. Su, J. Han, D. Zhang, and Z. Chen, "Fabrication and good ethanol sensing of biomorphic $\mathrm{SnO}_{2}$ with architecture hierarchy of butterfly wings," Nanotechnology, vol. 20, no. 49, Article ID 495502, 2009.

[9] L. Jin, J. Zhai, L. Heng et al., "Bio-inspired multi-scale structures in dye-sensitized solar cell," Journal of Photochemistry and Photobiology C: Photochemistry Reviews, vol. 10, no. 4, pp. 149158, 2009.

[10] R. A. Potyrailo, H. Ghiradella, A. Vertiatchikh, K. Dovidenko, J. R. Cournoyer, and E. Olson, "Morpho butterfly wing scales demonstrate highly selective vapour response," Nature Photonics, vol. 1, no. 2, pp. 123-128, 2007.

[11] R. Boruah, P. Nath, D. Mohanta, G. A. Ahmed, and A. Choudhury, "Photonic properties of butterfly wing infiltrated with Agnanoparticles," Nanoscience and Nanotechnology Letters, vol. 3, no. 4, pp. 458-462, 2011.

[12] S. A. Boden and D. M. Bagnall, "Tunable reflection minima of nanostructured antireflective surfaces," Applied Physics Letters, vol. 93, no. 13, Article ID 133108, 2008.

[13] Q. Chen, G. Hubbard, P. A. Shields et al., "Broadband moth-eye antireflection coatings fabricated by low-cost nanoimprinting," Applied Physics Letters, vol. 94, no. 26, Article ID 263118, 2009. 
[14] L. Yang, Q. Feng, B. Ng, X. Luo, and M. Hong, "Hybrid motheye structures for enhanced broadband antireflection characteristics," Applied Physics Express, vol. 3, no. 10, Article ID 102602, 2010.

[15] C.-H. Sun, P. Jiang, and B. Jiang, "Broadband moth-eye antireflection coatings on silicon," Applied Physics Letters, vol. 92, no. 6, Article ID 061112, 2008.

[16] W. L. Min, B. Jiang, and P. Jiang, "Bioinspired self-cleaning antireflection coatings," Advanced Materials, vol. 20, no. 20, pp. 3914-3918, 2008.

[17] N. Yamada, T. Ijiro, E. Okamoto, K. Hayashi, and H. Masuda, "Characterization of antireflection moth-eye film on crystalline silicon photovoltaic module," Optics Express, vol. 19, no. s2, pp. A118-A125, 2011.

[18] S. A. Boden and D. M. Bagnall, "Sunrise to sunset optimization of thin film antireflective coatings for encapsulated, planar silicon solar cells," Progress in Photovoltaics: Research and Applications, vol. 17, no. 4, pp. 241-252, 2009.

[19] Y. C. Chang, G. H. Mei, T. W. Chang, T. J. Wang, D. Z. Lin, and C. K. Lee, "Design and fabrication of a nanostructured surface combining antireflective and enhanced-hydrophobic effects," Nanotechnology, vol. 18, no. 28, Article ID 285303, 2007.

[20] O. Sato, S. Kubo, and Z. Z. Gu, "Structural color films with lotus effects, superhydrophilicity, and tunable stop-bands," Accounts of Chemical Research, vol. 42, no. 1, pp. 1-10, 2009.

[21] F. Liu, Y. Liu, L. Huang et al., "Replication of homologous optical and hydrophobic features by templating wings of butterflies Morpho menelaus," Optics Communications, vol. 284, no. 9, pp. 2376-2381, 2011.

[22] D. Byun, J. Hong, Saputra et al., "Wetting characteristics of insect wing surfaces," Journal of Bionic Engineering, vol. 6, no. 1, pp. 63-70, 2009.

[23] W. Zhang, D. Zhang, T. Fan et al., "Novel photoanode structure templated from butterfly wing scales," Chemistry of Materials, vol. 21, no. 1, pp. 33-40, 2009.

[24] Q. Zhao, T. Fan, J. Ding, D. Zhang, Q. Guo, and M. Kamada, "Super black and ultrathin amorphous carbon film inspired by anti-reflection architecture in butterfly wing," Carbon, vol. 49, no. 3, pp. 877-883, 2011.

[25] X. Yang, Z. Peng, H. Zuo, T. Shi, and G. Liao, "Using hierarchy architecture of Morpho butterfly scales for chemical sensing: experiment and modeling," Sensors and Actuators A: Physical, vol. 167, no. 2, pp. 367-373, 2011.

[26] Y. Chen, J. Gu, S. Zhu, T. Fan, D. Zhang, and Q. Guo, "Iridescent large-area $\mathrm{ZrO}_{2}$ photonic crystals using butterfly as templates," Applied Physics Letters, vol. 94, no. 5, Article ID 053901, 2009.

[27] J. Huang, X. Wang, and Z. L. Wang, "Controlled replication of butterfly wings for achieving tunable photonic properties," Nano Letters, vol. 6, no. 10, pp. 2325-2331, 2006.

[28] W. Peng, X. Hu, and D. Zhang, "Bioinspired fabrication of magneto-optic hierarchical architecture by hydrothermal process from butterfly wing," Journal of Magnetism and Magnetic Materials, vol. 323, no. 15, pp. 2064-2069, 2011.

[29] R. T. Lee and G. S. Smith, "Detailed electromagnetic simulation for the structural color of butterfly wings," Applied Optics, vol. 48, no. 21, pp. 4177-4190, 2009.

[30] S. Kinoshita, S. Yoshioka, and J. Miyazaki, "Physics of structural colors," Reports on Progress in Physics, vol. 71, no. 7, Article ID 076401, 2008. 

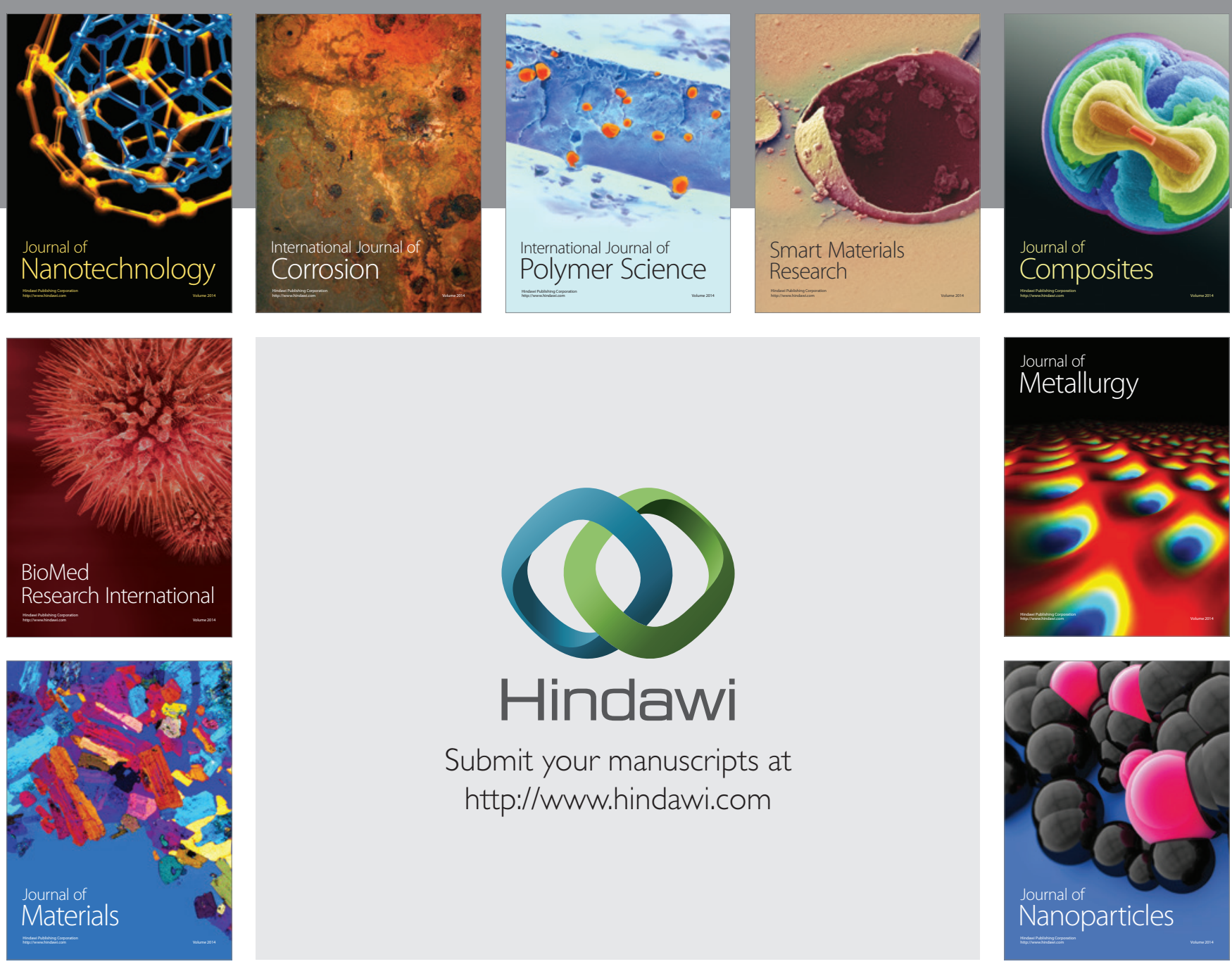

Submit your manuscripts at http://www.hindawi.com
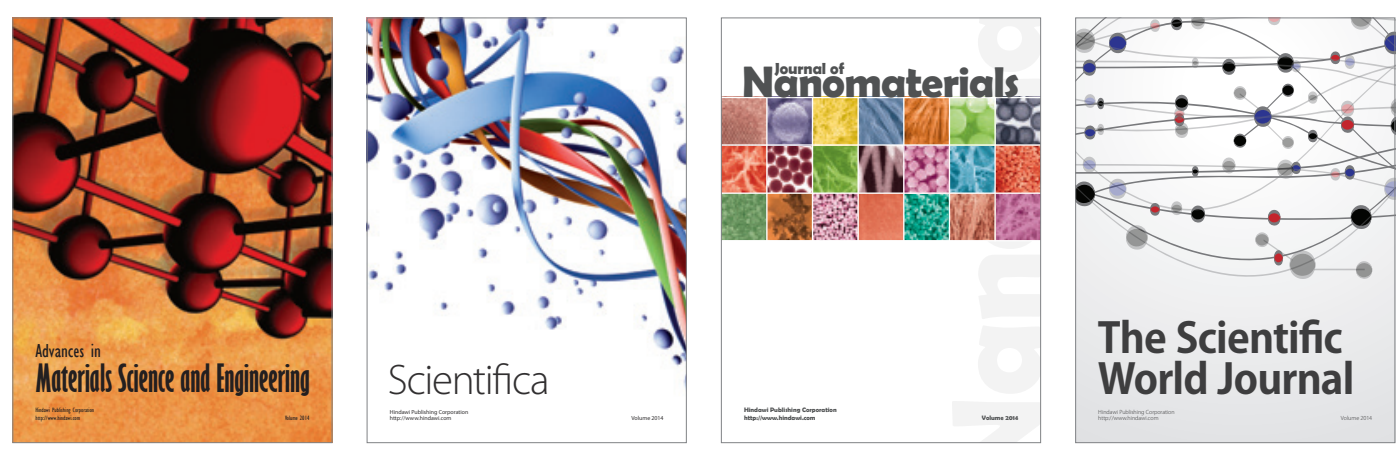

\section{The Scientific World Journal}
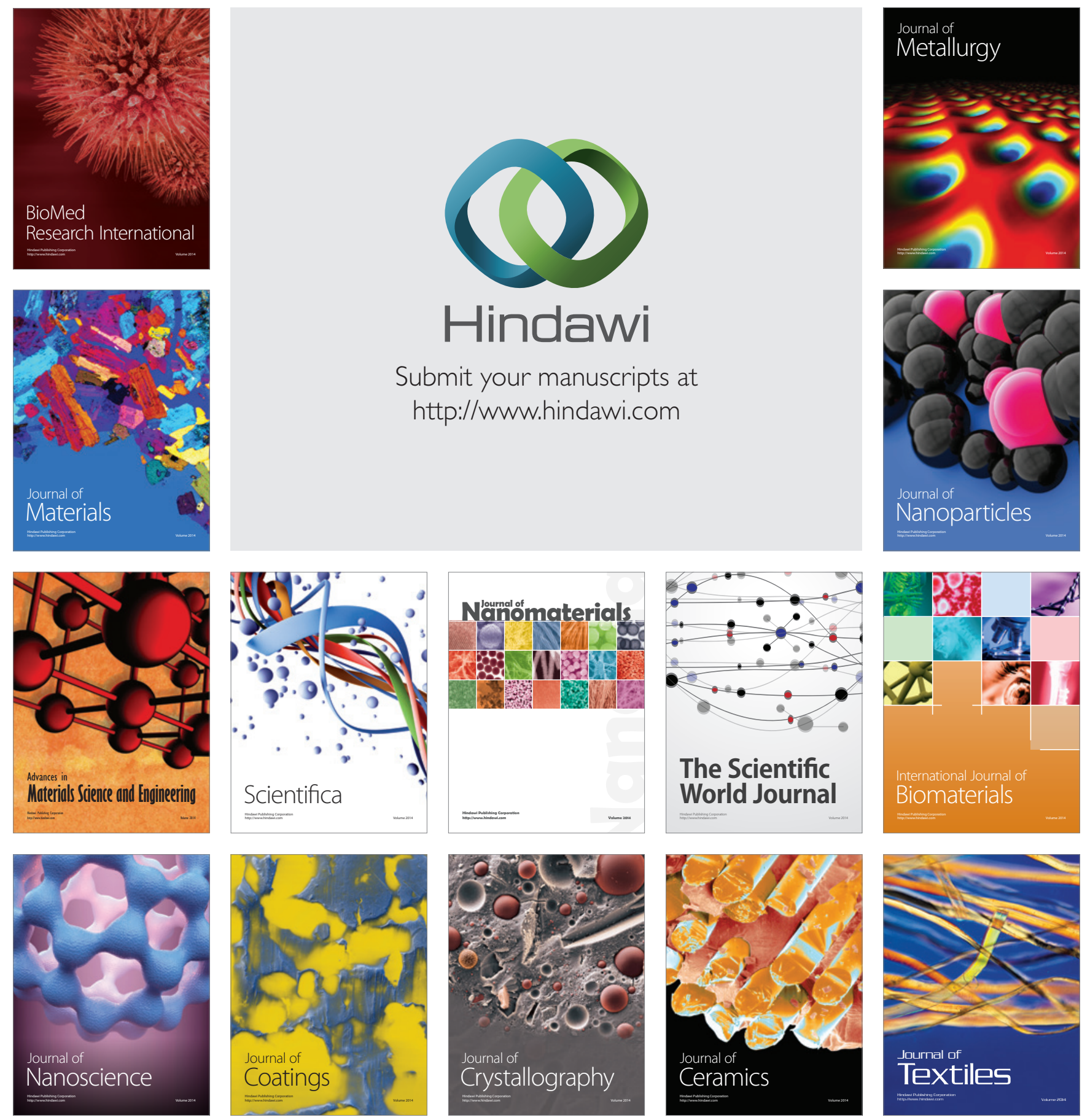